\title{
Efeitos da ampliação das exportações agropecuárias e agroindustriais na balança comercial e (re)distribuição da renda: uma análise de equilíbrio geral
}

Neiva de Araújo Marques ${ }^{1}$

Wilson da Cruz Vieira ${ }^{2}$

Viviani Silva Lírio ${ }^{3}$

Suely de Fátima Ramos Silveira ${ }^{4}$

\begin{abstract}
Resumo: O objetivo deste trabalho foi analisar os efeitos da ampliação das exportações agropecuárias e agroindustriais brasileiras sobre a balança comercial e (re)distribuição de renda entre fatores de produção, em um contexto de equilíbrio geral, tendo-se por base o ano de 1996. Utilizaram-se como referencial teórico a teoria de equilíbrio geral e como modelos analíticos uma Matriz de Contabilidade Social (MCS) e um Modelo Aplicado de Equilíbrio Geral (MAEG). Os multiplicadores da MCS calculados mostraram que os setores mais impactados, com a ampliação das exportações, foram Outras Indústrias, Outros Serviços e a instituição Família. Os resultados do MAEG, por sua vez, sugerem que houve favorecimento do fator capital em relação ao trabalho com a ampliação das exportações. Ambos os modelos (MCS e MAEG) apresentaram efeitos positivos e significativos na balança comercial brasileira, mas, com relação à (re)distribuição de renda entre os fatores de produção, não houve melhora significativa no padrão distributivo.
\end{abstract}

\footnotetext{
${ }^{1}$ Professora do Departamento de Administração da Universidade Federal do Mato Grosso (UFMT/MT).

${ }^{2}$ Professor do Departamento de Economia Rural da Universidade Federal de Viçosa (UFV/MG).wvieira@ufv.br

${ }^{3}$ Professora do Departamento de Economia Rural da Universidade Federal de Viçosa (UFV/MG).

${ }^{4}$ Professora do Departamento de Administração da Universidade Federal de Viçosa (UFV/MG).
} 
Palavras-chave: Exportações, Matriz de Contabilidade Social, equilíbrio geral, Brasil.

Classificação JEL: D58, Q17

Abstract: The objective of this work was to analyze the effects of the increase in the Brazilian agricultural and agro industrial exports upon the trade account and income distribution between labor and capital in a general equilibrium context. The general equilibrium analysis was used as theoretical framework and a Social Account Matrix (SAM) and a Computable General Equilibrium model (CGE) were used as analytical instruments. It was considered 1996 as base year and several simulations were conducted. The SAM multipliers calculated show that the most affected sectors with the export increases were Other Industries, Other Services and the Family Institution. The results obtained with the CGE show that the capital factor was favored relative to labor with the export increases. Both models show that the export increases improved the trade account, but there was not significant improvement in the distributive pattern.

Key words: Exports, Social Account Matrix, general equilibrium, Brazil.

JEL Classification: D58, Q17

\section{Introdução}

A capacidade da agricultura de impulsionar outros setores pode ser avaliada a partir dos resultados obtidos quando a produção agrícola é realizada. Há grande influência sobre os setores que estão a montante da agricultura, como os que produzem máquinas, adubos, defensivos (efeitos para trás), assim como há também efeitos sobre os setores produtivos que se situam a jusante da agricultura, como a agroindústria, o transporte, a armazenagem e a comercialização das safras (efeitos para frente). Esses efeitos evidenciam as ligações intersetoriais entre agricultura e os demais setores da economia, onde se identificam as interdependências e a participação setorial nos resultados econômicos de um país ou de uma região. 
Com a modernização da economia brasileira, há maior integração da agricultura com os demais setores, e, no período recente, a agricultura tem tido um papel importante na estabilização da economia e no equilíbrio externo com a ampliação das exportações agrícolas, além de ter sido a âncora do Plano Real contra a inflação, com saldo comercial setorial positivo da ordem de US $\$ 11,7$ bilhões, em 1997, e de US $\$ 25,85$ bilhões, em 2003. Os setores não-agrícolas, especialmente a partir da segunda metade da década de 1990, apresentaram saldos deficitários, tendo sido US\$ 10,90 bilhões, em 1995, e de US\$ 1,02 bilhão, em 2003 (Brasil, 2004).

Citam-se, como exemplo, as principais commodities agropecuárias e agroindustriais de exportação brasileira (complexo soja, café, suco de laranja, açúcar e carne bovina), cujas performances no total exportado pelo país mostraram-se entre estável e crescente ao longo da década de 1990 e início da década de 2000, mantendo-se em situação melhor que a dos setores não-agrícolas que apresentaram desempenho deficitário nesse mesmo período. Com referência ao complexo soja, o Brasil tem tido uma participação crescente no comércio de grãos e farelo de soja, exportando principalmente para a Europa e países asiáticos. A tendência de crescimento das exportações agropecuárias que marcou o final da década de 1990 pode ser explicada pelo aumento dos preços internacionais e pelo desenvolvimento de novas áreas de cultivo, principalmente no Cerrado brasileiro.

Esse desempenho das exportações brasileiras acontece em sintonia com importantes transformações que o país passou a experimentar a partir da década de 1990, como a estabilização econômica e a maior abertura ao comércio exterior. Tais transformações, de maneiras diversas, vêm afetando a economia brasileira, tendo gerado mudanças estruturais no cenário nacional em termos de atualização de conteúdo tecnológico dos processos produtivos e também das inter-relações entre os setores participantes da atividade econômica.

No caso específico deste trabalho, salienta-se, entre outras, a possibilidade de identificar e evidenciar até que ponto o aumento nas exportações brasileiras de produtos agropecuários e agroindustriais, especificamente no período mais recente, vêm contribuindo para a melhoria de vida dos brasileiros no que se refere à distribuição de renda entre fatores de produção e ao desempenho da balança comercial. 
Nesse sentido, o objetivo geral deste trabalho foi avaliar os efeitos da ampliação das exportações agropecuárias e agroindustriais brasileiras na balança comercial e na (re)distribuição de renda entre fatores de produção (capital e trabalho), em um contexto de equilíbrio geral, tendo-se como referência o ano de $1996^{5}$.

Especificamente, pretendeu-se:

a) Calcular os efeitos de aumentos marginais na demanda final sobre a produção setorial (multiplicadores), tendo por base uma matriz de contabilidade social (MCS) elaborada com informações da economia brasileira de 1996;

b) Estimar os efeitos de choques exógenos na demanda final (ampliação da exportação em relação a 1996) sobre produção setorial, uso dos fatores de produção e balança comercial;

c) Comparar os resultados obtidos no item b, a partir da MCS e do modelo aplicado de equilíbrio geral.

\section{Referencial Teórico}

Neste trabalho utilizou-se, como referencial teórico, a análise de equilíbrio geral ${ }^{6}$. A abordagem de equilíbrio geral possibilita preencher as lacunas existentes na análise de equilíbrio parcial, uma vez que focaliza a economia como um sistema completo composto por diversas unidades interdependentes. Segundo Bautista et al. (1998), a necessidade da análise de equilíbrio geral emerge quando se deseja capturar todas as interações que determinam os impactos nos diversos setores de uma dada economia. Güzel e Kuleshreshtha (1995), por sua vez, salientaram que a análise de equilíbrio parcial não apresenta fundamentação adequada para o tratamento das possíveis mudanças macroeconômicas sobre o setor agropecuário, em face do resto da economia. Segundo esses autores, se as ligações com o resto da economia são importantes, a análise de equilíbrio geral é mais apropriada.

\footnotetext{
${ }^{5}$ Trata-se do ano mais recente em que há Tabelas de Recursos e Usos disponibilizadas pelo IBGE em seu site (http://www.ibge.gov.br) à época da realização deste trabalho. ${ }^{6}$ Informações adicionais sobre a análise de equilíbrio geral podem ser encontradas, por exemplo, em Ginsburgh e Keyzer (1997) e Shoven e Whalley (1992).
} 
Sadoulet e de Janvry (1995) ilustraram o funcionamento de um modelo de equilíbrio geral multissetorial pelo qual se pode analisar os efeitos do comércio sobre a economia doméstica (Figura 1). Nesse modelo, o preço relativo é determinado pelas forças de oferta e demanda em dado mercado.

Figura 1 - Fluxos de um modelo de equilíbrio geral multissetorial

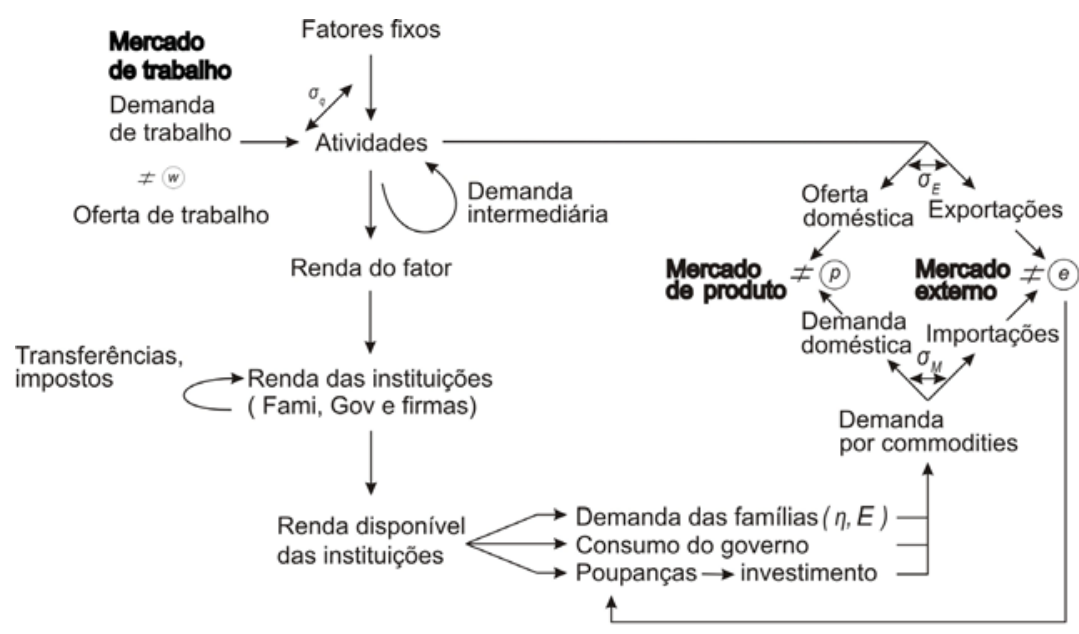

\footnotetext{
Em que:

o símbolo $\neq$ Prepresenta um mecanismo de mercado com preço de equilíbrio $p$;

$\sigma_{q}$ são elasticidades de substituição entre fatores de produção;

$\sigma_{M}$ são elasticidades de substituição entre importação e bens domésticos;

$\sigma_{E}$ são elasticidades de substituição entre produtos exportados e bens domésticos;

$\eta \in E$ são elasticidades de renda e de preço do consumo das famílias.
}

Fonte: Sadoulet e de Janvry (1995:352).

A partir da ampliação nas exportações, por exemplo, pode-se observar, no canto superior direito da Figura 1, toda a dinâmica que envolve a economia de um país ou região. A princípio, há aumento da oferta de bens e serviços para atender às demandas internas e externas. Como conseqüência disso, tem-se o aumento na demanda de fatores de produção (canto superior esquerdo da Figura 1), seguido de aumento na demanda de importações de alguns insumos necessários à produção. 
Tendo em vista que a demanda doméstica não diminui pelo simples fato de ampliar as exportações, observa-se que, pelo lado da produção, dado o comportamento maximizador de lucro, as ofertas doméstica e de exportação de bens e serviços serão definidas pelos preços relativos e pelas elasticidades de substituição. Pelo lado do mercado externo (mercado de câmbio), as importações formam a demanda e as exportações, a oferta de divisas. Os desequilíbrios no mercado doméstico entre oferta e demanda pelos diferentes bens e o desequilíbrio no mercado do câmbio são, simultaneamente, resolvidos por ajustes dos preços domésticos e da taxa de câmbio. Deste modo, atinge-se o fim do círculo com um novo conjunto de preços para bens domésticos e taxa de câmbio. Ocorre, então, nova rodada nas quais as decisões dos produtores são modificadas para se adaptar aos novos preços, à nova renda, e assim por diante. Isto continua até que o sistema econômico convirja para um conjunto de preços que assegure equilíbrio em todos os mercados. Ocorrem, portanto, alterações tanto no mercado de fatores quanto na balança comercial.

\section{Metodologia}

No presente trabalho utilizou-se, como instrumental analítico, uma Matriz de Contabilidade Social (MCS), construída com base nas últimas Tabelas de Recursos e Usos divulgadas pelo IBGE (1999) referentes ao ano de 1996 e informações das Contas Nacionais, do Relatório do Banco Central (1996) e do Tesouro Nacional. Essa matriz serviu de base para a construção de um modelo aplicado de equilíbrio geral.

A estrutura sucinta da MCS utilizada neste trabalho é apresentada na Tabela 1. Nessa estrutura, observa-se que, de modo geral, existem cinco tipos de contas: produtos, contas de fatores de produção (capital e trabalho), conta-corrente das instituições (famílias, firmas e governos), uma conta de capital e uma conta resto do mundo. 
Tabela 1 - Estrutura sucinta de uma Matriz de Contabilidade Social

\begin{tabular}{|c|c|c|c|c|c|c|c|c|}
\hline & Produtos & Trabalho & Firmas & Famílias & Governo & $\begin{array}{c}\text { Conta } \\
\text { Capital }\end{array}$ & $\begin{array}{c}\text { Resto do } \\
\text { Mundo }\end{array}$ & Total \\
\hline Produtos & $\begin{array}{l}\text { Consumo } \\
\text { Intermed. }\end{array}$ & & & $\begin{array}{l}\text { Consu- } \\
\text { mo }\end{array}$ & $\begin{array}{c}\text { Consu- } \\
\text { mo }\end{array}$ & $\begin{array}{l}\text { Investi- } \\
\text { mento }\end{array}$ & $\begin{array}{l}\text { Expor- } \\
\text { tação }\end{array}$ & $\begin{array}{c}\text { Deman- } \\
\text { da }\end{array}$ \\
\hline Trabalho & Salários & & & & & & & $\begin{array}{c}\text { Valor } \\
\text { Adicio- } \\
\text { nado }\end{array}$ \\
\hline Firmas & $\begin{array}{c}\text { Excedente } \\
\text { Operacional }\end{array}$ & & & & & & & Renda \\
\hline Famílias & & $\begin{array}{l}\text { Renda } \\
\text { trabalho }\end{array}$ & $\begin{array}{c}\text { Excedente } \\
\text { Operac }\end{array}$ & & Transf. & & & Renda \\
\hline Governo & $\begin{array}{c}\text { Impostos + } \\
\text { Tarifas }\end{array}$ & Taxas & Taxas & & & Capitais & & Receita \\
\hline $\begin{array}{l}\text { Conta } \\
\text { Capital }\end{array}$ & & $\begin{array}{c}\text { Pou- } \\
\text { pança }\end{array}$ & $\begin{array}{c}\text { Pou- } \\
\text { pança }\end{array}$ & & Poupança & & Capitais & $\begin{array}{c}\text { Poupan- } \\
\text { ça }\end{array}$ \\
\hline $\begin{array}{l}\text { Resto do } \\
\text { Mundo }\end{array}$ & Importação & $\begin{array}{l}\text { Pagamento } \\
\text { Fator }\end{array}$ & $\begin{array}{l}\text { Remessa } \\
\text { Lucro }\end{array}$ & & Juros & & & $\begin{array}{c}\text { Importa- } \\
\text { ção }\end{array}$ \\
\hline Total & Oferta & $\begin{array}{l}\text { Dispên- } \\
\text { dio }\end{array}$ & $\begin{array}{l}\text { Dispên- } \\
\text { dio }\end{array}$ & $\begin{array}{l}\text { Dispên- } \\
\text { dio }\end{array}$ & $\begin{array}{l}\text { Dispên- } \\
\text { dio }\end{array}$ & $\begin{array}{c}\text { Inves- } \\
\text { tim. }\end{array}$ & Trocas & \\
\hline
\end{tabular}

Fonte: Adaptado de Vieira (1998).

Ressalta-se que as Tabelas de Recursos e Usos de 1996, divulgadas pelo IBGE e utilizadas neste trabalho, envolvem 42 setores produtivos que foram agregados em 6 de acordo com suas características e interpretação do próprio IBGE, de modo a atender aos objetivos deste trabalho (Tabela 2).

Tabela 2 - Agregação e compatibilização entre a estrutura original de atividades e produtos do IBGE e a estrutura considerada neste trabalho

\begin{tabular}{|c|c|c|c|}
\hline Código & Setores Agregados & $\begin{array}{c}\text { Código Setores MIP* - } \\
\text { IBGE } 1996\end{array}$ & $\begin{array}{c}\text { Código do Produto Nível } \\
80 \text { MIP* - IBGE } 1996 \\
\end{array}$ \\
\hline AGR & Agropecuária & 01 & 01 a 11 \\
\hline OIND & Outras Indústrias & 02 a 13,18 a 21 e 34 & 12 a 26,32 a 42 e 65 \\
\hline AGI & Agroindústria & 14 a 17 e de 22 a 32 & 27 a 31 e 43 a 63 \\
\hline MAR & Margens & 35 e 36 & 66 e 67 \\
\hline IFIN & Intermediação financeira & 38 & 69 e 70 \\
\hline OSE & Outros Serviços & $33,37,39,40$ a 43 & 64,68 e 71 a 80 \\
\hline
\end{tabular}

Fonte: Elaborada pelos autores a partir de dados da MIP 1996 (IBGE, 1999).

Nota: $\left({ }^{*}\right)$ MIP = Matriz de Insumo-Produto. 
Os multiplicadores da MCS foram calculados de acordo com a metodologia descrita em Sadoulet e de Janvry (1995) (Tabela 3). O primeiro passo foi separar as contas endógenas das exógenas. Neste trabalho, apenas a conta Resto do Mundo foi considerada exógena.

Tabela 3 - MCS particionada em contas endógenas e exógenas

\begin{tabular}{l|c|c|c}
\hline \multicolumn{4}{c}{ Contas Endógenas (n) } \\
\begin{tabular}{l|c|c} 
Despesas das Contas \\
Exógenas (m)
\end{tabular} & Total \\
\hline Contas Endógenas (n) & $\mathrm{MX}$ & $\mathrm{F}$ & $\mathrm{X}$ \\
\hline Contas Exógenas (m) & $\mathrm{BX}$ & $\mathrm{L}$ & \\
\hline & $\mathrm{X}$ & & \\
\hline
\end{tabular}

Fonte: Sadoulet e de Janvry (1995:289).

Na estrutura esquemática apresentada na Tabela 3, X é o vetor da receita ou despesa total das contas endógenas; $\mathrm{F}$ é a soma do vetor das despesas das contas exógenas; $M$ é a matriz quadrada ( $\mathrm{n} \times \mathrm{n}$ ) de coeficientes das contas endógenas; B é a matriz retangular ( $\mathrm{m} \times \mathrm{n}$ ) dos coeficientes com contas exógenas, nas linhas, e endógenas, na coluna; e L é o vetor coluna das receitas das contas exógenas. Representando $\Delta$ como o operador de mudança, têm-se:

$\begin{array}{ll}\text { Matriz de multiplicadores } & (\mathrm{I}-\mathrm{M})^{-1} \\ \text { Vetor de choque } & \Delta \mathrm{F} \\ \text { Vetor de impactos } & \Delta \mathrm{X}=(\mathrm{I}-\mathrm{M})^{-1} \Delta \mathrm{F} \\ \text { Vazamentos } & \Delta \mathrm{L}=\mathrm{B} \Delta \mathrm{X}\end{array}$

Como critério para definição dos choques exógenos, aplicou-se percentuais de $15 \%$ e de $25 \%$ sobre o valor total das exportações do setor Agropecuário $^{7}$, referentes ao ano de 1996, o que corresponde a R \$76,84 milhões e R\$ 128,07 milhões, respectivamente. Esses valores, quando comparados com as exportações de 1996 dos demais setores, possuem a seguinte correspondência (Tabela 4):

\footnotetext{
7 Tomou-se como base, para definir esses percentuais, a variação total das exportações agropecuárias no período de 1996 a 2002 que representou mais de $15 \%$ neste período, considerando-se os valores das Tabelas de Recursos e Usos de 1996. Os valores obtidos foram deflacionados pelo índice IGP-OG da Fundação Getúlio Vargas.
} 
Tabelas 4 - Percentuais de choques (aumento das exportações) sofridos por cada setor

\begin{tabular}{lcc}
\hline Setores & \multicolumn{2}{c}{ Valores equivalentes } \\
\hline Agropecuária & $\mathbf{1 5 \%}$ & $\mathbf{2 5 \%}$ \\
\hline Outras Indústrias & $0,88 \%$ & $1,48 \%$ \\
\hline Agroindústria & $0,93 \%$ & $1,55 \%$ \\
\hline Margens & $6,50 \%$ & $10,83 \%$ \\
\hline Intermediações Financeiras & $42,20 \%$ & $70,34 \%$ \\
\hline Outros Serviços & $8,53 \%$ & $14,21 \%$ \\
\hline
\end{tabular}

Fonte: Valores calculados pelos autores com base na MCS construída para este trabalho.

Nota-se que, embora os percentuais calculados sejam bem diferentes, os valores referentes à ampliação das exportações ( $\mathrm{R} \$ 76,84$ milhões e $\mathrm{R} \$ 128,07$ milhões) foram considerados os mesmos para todos os setores. Desta forma, puderam-se fazer comparações diretas dos resultados obtidos pelos diversos setores. Observa-se que esses percentuais foram bem pequenos no caso de setores com maior participação relativa na economia brasileira, como Outras Indústrias e Agroindústria.

Na implantação do modelo aplicado de equilíbrio geral (MAEG), utilizou-se o sistema GAMS/MPSGE (Generalized Algebraic Modeling System/ Mathematical Programming System for General Equilibrium) (Brooke et al., 1996), cuja formulação matemática encontra-se em Rutherford (2004). Foram considerados os seguintes pressupostos: a) Considerou-se um modelo de economia aberta; b) O setor externo (outros países) não foi modelado explicitamente; c) Baseou-se na suposição de Hecksher-Ohlin em que os bens domésticos, importados e exportados são substitutos perfeitos; d) Para utilizar o GAMS/MPSGE, a MCS foi reescrita de forma que, no equilíbrio, as contas (linhas e colunas) que mantinham valores idênticos para colunas e linhas (matriz quadrada), agora se transforma no formato retangular em que linhas e colunas zeram. Este formato enfatiza como a estrutura do programa GAMS/MPSGE é conectado à base de dados. Cada mercado é representado por uma linha e as colunas representam os setores produtivos e consumidores. Uma coluna extra e uma linha extra foram acrescentadas para representar o consumo doméstico agregado e o correspondente índice de preços; e) Na obtenção da MCS retangular, simplificou-se sua estrutura para 
facilitar sua aplicação. Para cada setor, juntaram-se tarifas e impostos. Como o programa GAMS/MPSGE não aceita tributação no consumo, subtraiu-se da arrecadação geral do governo o total de tributos aplicados no mercado de capitais. Apenas os tributos sobre a renda de trabalho e lucro das firmas foram considerados explicitamente; f) Em todos os setores, considerou-se função de produção do tipo Leontief (elasticidade de substituição igual a zero); g) Utilizou-se o fechamento neoclássico e, para a normalização, considerou-se, como numéraire o índice da taxa de câmbio; e h) Por simplicidade, tarifas e impostos foram aplicados apenas no fator capital.

A solução do MAEG passou por duas fases: a primeira, para a obtenção dos valores dos parâmetros a partir da MCS (calibração); e a segunda, para a obtenção da solução-base a partir da utilização do modelo em sistemas de equações não-lineares denominados GAMS/MPSGE. Tendo em mãos a solução-base, aplicou-se o choque nas exportações de cada um dos setores, individualmente, obtendo-se uma nova solução, com o ajustamento para setores, consumidores e demais variáveis endógenas.

\section{Resultados e Discussão}

São apresentados, inicialmente, os resultados relativos à MCS (cálculo de multiplicadores e efeitos de choques exógenos) e, em seguida, aqueles obtidos com o modelo aplicado de equilíbrio geral (MAEG). Ao final, comparam-se os resultados obtidos com os dois modelos.

A Tabela 5 mostra a MCS construída particionada em contas endógenas e exógena, referente ao ano de 1996, que corresponde ao equilíbrio inicial para fins de comparação com os equilíbrios pós-choques das simulações realizadas neste trabalho.

De acordo com a Tabela 5, observa-se que o Valor da Produção (X) é o resultado tanto de $(\mathrm{MX}+\mathrm{F})$ como de $(\mathrm{MX}+\mathrm{BX})$, o que garante que a MCS está devidamente balanceada e que o tratamento dado às variáveis está de acordo com o descrito por Sadoulet e de Janvry (1995).

Na coluna MX constata-se que os valores individuais de cada linha representam o valor total de cada setor, subtraído o valor da exportação setorial. No cômputo geral da economia, o valor da Agropecuária, por exemplo, tem uma participação de 3,47\% do total geral (X), sem as expor- 
tações. Ao adicionar o valor das exportações do setor, essa participação passa para $3,49 \%$, sendo pouco significativa para a economia nacional. No entanto, a importância relativa da Agropecuária no desenvolvimento dos países tem sido inegável, seja para garantir segurança alimentar e/ou financiar o desenvolvimento de setores industriais incipientes.

Tabela 5 - Contas endógenas e exógena da matriz de contabilidade social - MCS - Brasil, 1996 (em R\$ milhões e em percentual)

\begin{tabular}{|c|c|c|c|c|c|c|}
\hline & \multicolumn{2}{|c|}{ Contas endógenas } & \multicolumn{2}{|c|}{ Conta exógena } & \multicolumn{2}{|l|}{ Total } \\
\hline & MX & $\%$ & $\begin{array}{l}\text { Resto do } \\
\text { Mundo (F) }\end{array}$ & $\%$ & $(\mathrm{X})$ & $\%$ \\
\hline Agropecuária & $105.252,35$ & 3,47 & 512,27 & 0,53 & $105.764,62$ & 3,49 \\
\hline Outras ind. & $488.936,39$ & 16,14 & $8.635,66$ & 8,94 & $497.572,05$ & 16,42 \\
\hline Agroindústria & $284.651,21$ & 9,40 & $8.250,67$ & 8,54 & $292.901,88$ & 9,67 \\
\hline Margens & $43.232,60$ & 1,43 & $1.182,02$ & 1,22 & $44.414,62$ & 1,47 \\
\hline Interm. financ. & $71.206,95$ & 2,35 & 182,07 & 0,19 & $71.389,03$ & 2,36 \\
\hline Outros serviços & $464.697,60$ & 15,34 & 901,30 & 0,93 & $465.598,89$ & 15,37 \\
\hline Trabalho & $229.649,17$ & 7,58 & - & - & $229.649,17$ & 7,58 \\
\hline Firmas & $290.869,55$ & 9,60 & - & - & $290.869,55$ & 9,60 \\
\hline Famílias & $481.039,47$ & 15,88 & $5.773,13$ & 5,98 & $486.812,61$ & 16,07 \\
\hline Governo & $256.606,18$ & 8,47 & - & - & $256.606,18$ & 8,47 \\
\hline Capital & $216.880,45$ & 7,16 & $71.182,98$ & 73,67 & $288.063,42$ & 9,51 \\
\hline MX & $2.933 .021,91$ & 96,81 & $96.620,09$ & 100,00 & $3.029 .642,00$ & 100,00 \\
\hline BX & $96.620,09$ & 3,19 & 0 & & & \\
\hline $\mathbf{X}$ & $3.029 .642,00$ & 100,00 & & & & \\
\hline
\end{tabular}

Fonte: Dados da pesquisa.

O setor Outras Indústrias representou $16,14 \%$ do total geral das receitas (X), o que confirma a sua grande importância para a economia; no entanto, observa-se que a Agroindústria representou sozinha, 9,40\% de (X). Considerando-se que o setor Agropecuário é um grande ofertante dos insumos utilizados na Agroindústria, constatou-se que as interligações dos setores são relevantes, já que alterações em um deles resultam em alterações nos demais setores da economia. 
Efeitos da ampliação das exportações Agropecuárias e Agroindustriais na Balança Comercial e (re)distribuição da renda: uma análise de equilíbrio geral

\subsection{Efeitos multiplicadores da matriz de contabilidade social}

Os multiplicadores ilustram a importante contribuição da abordagem da MCS, destacando-se que estes consideram os efeitos dos impactos da aplicação de choques exógenos na produção setorial e uso de fatores de produção. Com base nas informações da Tabela 5, calcularam-se os multiplicadores da MCS $\left\{(I-M)^{-1}\right\}$ (Tabela 6).

A interpretação das seis primeiras colunas da Tabela 6 indica que um aumento de uma unidade nas exportações de produtos de cada um dos setores induz ao aumento de produção de 2,22 unidades no setor Agropecuário; 5,72 no de "Outras Indústrias"; 3,96 no de "Agroindústria"; 1,54 no de "Margens"; 2,60 no de "Intermediações Financeiras" e 6,11 no de "Outros Serviços". Induz, ainda, ao aumento da renda das famílias e do governo em uma variação de 4,83 a 5,19 e de 2,23 a 2,39 unidades monetárias, respectivamente; de 2,38 nos investimentos; e de 3,33 e 2,33 no capital e trabalho, respectivamente. Observa-se que os setores mais impactados a partir do aumento de uma unidade nas exportações de cada um dos setores da matriz de multiplicadores da MCS foram "Outras Indústrias" e "Outros Serviços" e a instituição "Família".

Tabela 6 - Multiplicadores da MCS - Brasil, 1996

\begin{tabular}{lccccccccccc}
\hline & 01 & 02 & 03 & 04 & 05 & 06 & 07 & 08 & 09 & 10 & 11 \\
& AGP & OIND & AGI & MAR & IFIN & OSERV & TRAB & FIRMA & FAM & GOV & CAP \\
AGP & $\mathbf{2 , 2 2}$ & 0,97 & 1,23 & 1,11 & 1,13 & 1,12 & 1,18 & 1,09 & 1,19 & 1,13 & 1,08 \\
OIND & 4,68 & $\mathbf{5 , 7 2}$ & 4,37 & 4,95 & 4,76 & 4,77 & 4,81 & 4,93 & 4,81 & 4,77 & 5,21 \\
AGI & 2,86 & 2,71 & $\mathbf{3 , 9 6}$ & 3,11 & 3,12 & 3,12 & 3,25 & 2,98 & 3,26 & 3,12 & 2,94 \\
MAR & 0,43 & 0,43 & 0,43 & $\mathbf{1 , 5 4}$ & 0,47 & 0,46 & 0,48 & 0,45 & 0,48 & 0,46 & 0,45 \\
IFIN & 0,71 & 0,70 & 0,69 & 0,82 & $\mathbf{2 , 6 0}$ & 0,77 & 0,80 & 0,74 & 0,81 & 0,77 & 0,74 \\
SERV & 4,55 & 4,41 & 4,45 & 5,15 & 5,31 & $\mathbf{6 , 1 1}$ & 5,28 & 4,89 & 5,29 & 5,29 & 4,85 \\
TRAB & 2,33 & 2,26 & 2,28 & 2,82 & 2,88 & 2,71 & $\mathbf{3 , 5 2}$ & 2,37 & 2,52 & 2,49 & 2,38 \\
F IRMA & 3,33 & 2,96 & 2,93 & 3,17 & 3,28 & 3,21 & 3,10 & $\mathbf{3 , 9 7}$ & 3,10 & 3,05 & 3,01 \\
FAM & 4,83 & 4,58 & 4,64 & 5,29 & 5,45 & 5,19 & 5,92 & 5,26 & $\mathbf{5 , 9 5}$ & 5,55 & 5,06 \\
GOV & 2,30 & 2,23 & 2,31 & 2,39 & 2,50 & 2,39 & 2,40 & 2,55 & 2,34 & $\mathbf{3 , 3 7}$ & 2,78 \\
CAP & 2,38 & 2,15 & 2,14 & 2,31 & 2,39 & 2,33 & 2,27 & 2,81 & 2,26 & 2,38 & $\mathbf{3 , 2 6}$ \\
\hline
\end{tabular}

Fonte: Dados da pesquisa.

Nota: AGP - Agropecuário; OIND - Outras Indústrias; AGI - Agroindústria; MAR - Margens; IFIN - Intermediações Financeiras; OSERV - Outros Serviços; TRAB - Trabalho; FAM - Família; GOV - Governo e CAP - Capital. 
Uma das justificativas para que o aumento nas exportações Agropecuárias tenha resultado em aumentos mais que proporcionais na instituição Família (Tabela 6, Coluna 1) foi o fato de esse setor ser mais intensivo em mão-de-obra, sendo fundamental para o crescimento da economia nacional e grande gerador de empregos. No caso de Outras Indústrias, observa-se que está incorporada nesse setor grande parte dos fornecedores de insumos agropecuários. Isso mostra que qualquer aumento nas exportações Agropecuárias provocará incrementos nos setores que estão à montante dele, como, por exemplo, a indústria de máquinas e tratores, veículos, químicos. Quando se trata do setor “Outros Serviços”, constatase que, para que haja possibilidade de se aumentar as exportações do país, é necessário que haja infra-estrutura de serviços que possibilite o escoamento desses produtos. Um resultado que chamou a atenção foi o aumento de apenas 0,43 na produção do setor Margens, uma vez que este é o responsável por todo comércio e transporte do país.

Era esperado que o impacto da Agroindústria sobre a Agropecuária induzisse um crescimento maior (Tabela 6, Coluna 3). No entanto, o multiplicador 1,23 pode ser considerado relevante, na medida em que se trata de um setor formado apenas das atividades agrícolas e pecuárias em detrimento dos demais que agregam praticamente toda a economia, como é o caso de Outras Indústrias que representa toda a indústria de transformação, excetuando-se apenas a Agroindústria.

Nas colunas 4 e 5 (Tabela 6), os setores Margens e Intermediações Financeiras, respectivamente, apresentaram multiplicadores muito maiores para os outros setores do que para eles próprios. Os setores mais beneficiados foram Outras Indústrias, Outros Serviços e a instituição Família. Esses resultados podem ser explicados pelo fato de os setores Margens e Intermediações Financeiras, sozinhos, não alavancarem crescimento econômico, uma vez que eles se localizam no final do fluxo (cadeia) e prosperam à medida que os outros se desenvolvem também, ou seja, são voltados para contribuir para o desenvolvimento.

O maior multiplicador apresentado nos resultados foi do setor Outros Serviços 6,11 (Tabela 6, Coluna 6), destacando-se que ele incorpora toda a indústria de prestação de serviços do país, cuja representatividade econômica é bem significativa. É um setor que tem se mostrado dinâmico no desenvolvimento econômico recente de grande parte dos países desenvolvidos e em desenvolvimento. 
As cinco últimas colunas da Tabela 6 mostram o impacto de injeções nas instituições e nos fatores de produção. Verifica-se que o aumento de uma unidade monetária nas Contas Família, Governo e Capital representou um aumento de 4,81, 4,77 e 5,21 em Outras Indústrias; de 5,29, 5,29 e 4,85 em Outros Serviços; e de 5,95, 5,55 e 5,06 em Famílias, respectivamente. O comportamento dos fatores de produção (Trabalho e Firma) foi semelhante, dando um aumento de 4,81 e 4,93 em Outras Indústrias; de 5,28 e 4,89 em Outros Serviços; e de 5,92 e 5,26 em Famílias, respectivamente. Estes foram os maiores impactos ocorridos na economia dado um aumento de uma unidade nas exportações desses setores.

Ao se analisar o resultado das linhas, verifica-se que a relação de consumo de cada setor com ele mesmo (diagonal principal) foi muito maior do que com os demais. Destaca-se, mais uma vez, que os setores Outros Serviços e Outras Indústrias e a instituição Família apresentaram os maiores multiplicadores, enquanto os demais valores em linha foram muito semelhantes. No caso da diagonal principal, a justificativa para esses multiplicadores elevados foi que o estímulo recebido por cada setor, individualmente, para expandir a exportação, recaiu sobre o próprio, fazendo com que sua produção aumentasse significativamente em relação aos demais.

\subsection{Efeitos de choques exógenos aplicados aos setores da MCS}

Nesta seção apresentam-se os resultados dos choques exógenos (ampliação das exportações) aplicados à MCS particionada (Tabela 5). A amplitude dos choques, que podem ser estudados pela MCS, deriva-se diretamente da escolha das contas exógenas, que, neste estudo, foi a conta Resto do Mundo, sendo então realizadas as simulações de mudanças nas exportações. Nas simulações 1 e 2, a ampliação das exportações de produtos de todos os setores, individualmente, representou variações de $\Delta=\mathrm{R} \$$ 76,84 milhões e de $\Delta=\mathrm{R} \$ 128,07$ milhões, critério definido na metodologia do trabalho, tendo-se obtido os resultados mostrados na Tabela 7.

Numa comparação dos resultados coluna a coluna (Tabela 7) a partir da variação $\Delta=\mathrm{R} \$ 76,84$ milhões (primeira simulação), observa-se que o setor Agropecuário impacta positivamente todos os setores econômicos, incluindo as instituições. Verifica-se que a mesma variação aplicada aos de- 
mais setores resultaram em respostas semelhantes em termos de resultados numéricos, com a diferença de que o setor Agropecuário é bem menor, em termos relativos, do que todos os demais setores agregados neste estudo.

Observa-se que tanto os valores apresentados nos cenários 2 e 3 (simulação 1 - R \$76,84 milhões) quanto aqueles apresentados nos cenários 8 e 9 (simulação 2 - R \$ 128,07 milhões) são muito semelhantes entre si devido, possivelmente, ao pequeno montante de aumento das exportações nos maiores setores da economia. Por exemplo, enquanto $\mathrm{R}$ \$ 76,84 milhões representam 15\% das exportações agropecuárias e R \$ 128,07 milhões representam $25 \%$ no ano de 1996, estes mesmos valores correspondem, respectivamente, a apenas $0,88 \%$ e $1,48 \%$ das exportações do setor Outras Indústrias.

Verifica-se, também, que não há praticamente diferenças significativas entre os diferentes cenários, nos aumentos por fatores de produção (trabalho e capital), considerando-se ambas as simulações. Portanto, os benefícios seriam muito semelhantes entre os setores considerados. Por outro lado, os resultados apontaram para uma melhora na balança comercial com o aumento das exportações. Entretanto, ficou difícil precisar a magnitude dessa melhora, pois não foi computado o volume de importações.

Os resultados mostrados na Tabela 7 indicam que, com a ampliação das exportações, houve aumento na demanda por ambos os fatores de produção, ressaltando-se que a variação do valor total demandado de trabalho é mais que proporcional ao aumento na demanda por capital (cenários 1, 4, 5, 6, 7, 10 e 11) ${ }^{8}$. Destaca-se que somente o setor Agropecuário apresentou a variação do valor total de mão-de-obra proporcionalmente menor do que a variação do valor do capital.

Dada a natureza da estrutura da MCS, cujas pressuposições são de não existência de substituição entre fatores de produção e preços fixos, não deu para captar todos os efeitos caso se considerasse maior flexibilidade de preços e das formas funcionais utilizadas. No entanto, faz-se mister salientar a importância de tal metodologia como possibilidade de conhecimento mais específico das interligações entre os setores selecionados, bem como essa matriz serviu de base ao modelo aplicado de equilíbrio geral, que adota pressupostos mais flexíveis.

${ }^{8}$ Assumiu-se capacidade ociosa na economia brasileira no uso desses fatores. 

e (re)distribuição da renda: uma análise de equilíbrio geral

Tabela 7 - Efeitos econômicos de choques nos setores da MCS - ampliações de $\mathrm{R} \$ 76,84$ milhões e $\mathrm{R} \$ 128,07$ milhões nas exportações de cada setor

\begin{tabular}{|c|c|c|c|c|c|c|}
\hline $\begin{array}{c}\mathrm{R} \$ 76,84 \\
\text { milhões }\end{array}$ & $\begin{array}{c}\text { Cenário } \\
1 \\
\end{array}$ & $\begin{array}{c}\text { Cenário } \\
2 \\
\end{array}$ & $\begin{array}{c}\text { Cenário } \\
3 \\
\end{array}$ & $\begin{array}{c}\text { Cenário } \\
4 \\
\end{array}$ & $\begin{array}{c}\text { Cenário } \\
5 \\
\end{array}$ & $\begin{array}{c}\text { Cenário } \\
6 \\
\end{array}$ \\
\hline Simulação 1 & AGR & OIND & AGI & MAR & IFIN & OSERV \\
\hline Agropecuário & 0,64 & 0,55 & 0,57 & 0,56 & 0,57 & 0,57 \\
\hline Outras ind. & 1,81 & 1,82 & 1,80 & 1,81 & 1,81 & 1,81 \\
\hline Agroindústria & 2,89 & 2,89 & 2,92 & 2,90 & 2,90 & 2,90 \\
\hline Margens & 2,73 & 2,73 & 2,73 & 2,92 & 2,74 & 2,74 \\
\hline Interm. financ & 0,33 & 0,33 & 0,33 & 0,34 & 0,53 & 0,34 \\
\hline Outros Serviços & 0,27 & 0,27 & 0,27 & 0,28 & 0,28 & 0,29 \\
\hline Trabalho & 0,08 & 0,08 & 0,08 & 0,09 & 0,10 & 0,09 \\
\hline Firmas & 0,09 & 0,08 & 0,08 & 0,08 & 0,09 & 0,08 \\
\hline Famílias & 1,26 & 1,26 & 1,26 & 1,27 & 1,27 & 1,27 \\
\hline Governo & 0,07 & 0,07 & 0,07 & 0,07 & 0,07 & 0,07 \\
\hline Capital & 24,76 & 24,75 & 24,75 & 24,76 & 24,76 & 24,76 \\
\hline $\begin{array}{c}\mathrm{R} \$ 128,07 \\
\text { milhões }\end{array}$ & $\begin{array}{c}\text { Cenário } \\
7 \\
\end{array}$ & $\begin{array}{c}\text { Cenário } \\
8 \\
\end{array}$ & $\begin{array}{c}\text { Cenário } \\
9 \\
\end{array}$ & $\begin{array}{c}\text { Cenário } \\
10 \\
\end{array}$ & $\begin{array}{c}\text { Cenário } \\
11 \\
\end{array}$ & $\begin{array}{c}\text { Cenário } \\
12 \\
\end{array}$ \\
\hline Simulação 2 & AGR & OIND & AGI & MAR & IFIN & OSERV \\
\hline Agropecuária & 0,75 & 0,60 & 0,63 & 0,62 & 0,62 & 0,62 \\
\hline Outras Ind. & 1,85 & 1,88 & 1,85 & 1,86 & 1,86 & 1,86 \\
\hline Agroindústria & 2,94 & 2,93 & 2,98 & 2,95 & 2,95 & 2,95 \\
\hline Margens & 2,78 & 2,78 & 2,78 & 3,09 & 2,79 & 2,79 \\
\hline Interm. Financ & 0,38 & 0,38 & 0,38 & 0,40 & 0,72 & 0,39 \\
\hline Outros Serv. & 0,32 & 0,31 & 0,32 & 0,33 & 0,34 & 0,36 \\
\hline Trabalho & 0,13 & 0,13 & 0,13 & 0,16 & 0,16 & 0,15 \\
\hline Firmas & 0,15 & 0,13 & 0,13 & 0,14 & 0,14 & 0,14 \\
\hline Famílias & 1,31 & 1,30 & 1,31 & 1,32 & 1,33 & 1,32 \\
\hline Governo & 0,11 & 0,11 & 0,11 & 0,12 & 0,12 & 0,12 \\
\hline Capital & 24,79 & 24,78 & 24,78 & 24,79 & 24,79 & 24,79 \\
\hline
\end{tabular}

Fonte: Dados da pesquisa.

\subsection{Efeitos de choques exógenos aplicados ao modelo computável de equilíbrio geral}

Para construir o modelo aplicado de equilíbrio geral (MAEG) utilizouse a estrutura básica da MCS com algumas pressuposições mais flexíveis. Ao simular choques exógenos na economia (aumento das exportações), 
o MAEG pode fornecer uma estrutura útil para análise de política num ambiente em que mudanças nos preços relativos (tal como a taxa de câmbio) e as mudanças resultantes nos incentivos são importantes determinantes de seus resultados.

Realizaram-se as simulações 3 e 4 com o MAEG, aplicando-se choques exógenos nos diferentes setores econômicos, idênticos àqueles aplicados no modelo da MCS. Essa decisão mostrou-se pertinente haja vista a necessidade de manter uma base de comparação na análise dos resultados obtidos em todas as simulações.

Os resultados das simulações 3 (cenários 13 a 18) e 4 (cenários 19 a 24), com o MAEG, mostrados na Tabela 8, indicam que aumentos de $15 \%$ e de $25 \%$ nas exportações do setor Agropecuário (o que corresponde, respectivamente, a $\mathrm{R} \$ 76,84$ milhões e $\mathrm{R} \$ 128,07$ milhões) induzem crescimentos de $0,2 \%$ e $0,5 \%$ nas produções desse setor, respectivamente. Observam-se decréscimos nas quantidades demandadas por produtos de Outras Indústrias e de Outros Serviços, numa variação de - $0,1 \%$ a - $0,5 \%$ e de $-0,8 \%$ a $-1,80 \%$, respectivamente. Essa queda, que se repete em todos os cenários em maior, menor ou idêntica proporção, pode ser explicada tanto pelo aumento nas importações de insumos para atender à produção de exportação, como também pode ser que outros setores da economia doméstica tenham adquirido produtos e serviços para atender essa ampliação de produção. Por outro lado, há aumentos na demanda por produtos da Agroindústria, Margens e Intermediações Financeiras da ordem de 2,5\% e $4,5 \%, 4,9 \%$ e $9,10 \%$, e de $0,2 \%$ e $0,30 \%$, respectivamente.

Os resultados apresentados na Tabela 8 indicam ainda que os preços dos produtos Agropecuários (AGROP), de Outras Indústrias (OIND) e da Agroindústria (AGI), diante de tais "choques", mostraram-se com tendência a aumentos numa variação entre 0,70\% e 8,70\%. Todavia, há queda nos preços de Margens (MAR), Intermediações Financeiras (IFIN) e Outros Serviços (OSERV) que podem ser explicados a partir da pressuposição de inexistência de inflação no modelo utilizado neste trabalho. Para manter a economia numa situação de equilíbrio (geral), isenta de inflação, o modelo necessita ajustar-se de modo que alguns preços tenderão à queda, enquanto outros sofrem aumento.

Verifica-se que o maior aumento no valor total exportado (Tabela 8, Cenário 19) ocorre quando se aplica um "choque” no próprio setor Agro- 
pecuário, na simulação 4, com uma expansão de $25 \%$ nas exportações deste setor. Nesta simulação, mais uma vez se evidencia a importância da Agropecuária para a balança comercial.

Tabela 8 - Efeitos de choques (aumento) nas exportações brasileiras em setores econômicos selecionados

\begin{tabular}{|c|c|c|c|c|c|c|}
\hline $\begin{array}{c}\mathrm{R} \$ 76,84 \\
\text { milhões }\end{array}$ & $\begin{array}{c}\text { Cenário } \\
13\end{array}$ & $\begin{array}{c}\text { Cenário } \\
14\end{array}$ & $\begin{array}{c}\text { Cenário } \\
15\end{array}$ & $\begin{array}{c}\text { Cenário } \\
16\end{array}$ & $\begin{array}{c}\text { Cenário } \\
17\end{array}$ & $\begin{array}{c}\text { Cenário } \\
18\end{array}$ \\
\hline Simulação 3 & AGR & OIND & AGI & MAR & IFIN & OSERV \\
\hline AGR & 0,20 & 0,00 & 0,00 & 0,00 & 0,00 & 0,00 \\
\hline OIND & $-0,20$ & $-0,10$ & $-0,20$ & $-0,10$ & $-0,10$ & $-0,10$ \\
\hline AGI & 2,50 & 2,20 & 2,30 & 1,80 & 1,80 & 1,90 \\
\hline MAR & 4,90 & 4,40 & 4,40 & 3,80 & 3,50 & 3,70 \\
\hline IFIN & 0,20 & 0,20 & 0,10 & 0,10 & 0,50 & 0,10 \\
\hline OSERV & $-1,00$ & $-0,90$ & $-0,90$ & $-0,80$ & $-0,80$ & $-0,80$ \\
\hline EX & 182,70 & 162,90 & 163,40 & 127,20 & 129,60 & 137,10 \\
\hline IM & 33,50 & 29,40 & 29,40 & 22,10 & 22,60 & 24,20 \\
\hline W & $-1,00$ & $-1,00$ & $-1,00$ & $-0,90$ & $-0,90$ & $-0,90$ \\
\hline PAGR & 5,10 & 4,80 & 4,90 & 4,20 & 4,30 & 4,40 \\
\hline POIND & 0,90 & 0,80 & 0,90 & 0,70 & 0,80 & 0,80 \\
\hline PAGI & 1,40 & 1,30 & 1,30 & 1,10 & 1,10 & 1,20 \\
\hline PMAR & $-15,00$ & $-14,20$ & $-14,40$ & $-12,50$ & $-12,60$ & $-12,90$ \\
\hline PIFIN & $-13,60$ & $-12,90$ & $-13,10$ & $-11,30$ & $-11,40$ & $-11,70$ \\
\hline POSERV & $-10,50$ & $-9,90$ & $-10,10$ & $-8,70$ & $-8,80$ & $-9,00$ \\
\hline PFX & 0,00 & 0,00 & 0,00 & 0,00 & 0,00 & 0,00 \\
\hline PL & $-43,70$ & $-41,50$ & $-42,10$ & $-36,40$ & $-36,80$ & $-37,70$ \\
\hline PK & 11,80 & 17,10 & 17,30 & 15,00 & 15,20 & 15,50 \\
\hline PW & $-4,20$ & $-4,00$ & $-4,10$ & $-3,50$ & $-3,60$ & $-3,60$ \\
\hline PT & 10,60 & 10,10 & 10,20 & 8,80 & 8,90 & 9,10 \\
\hline FAM & $-11,83$ & $-11,23$ & $-11,39$ & $-9,87$ & $-9,99$ & $-10,23$ \\
\hline GOV & 6,92 & 6,57 & 6,67 & 5,72 & 5,79 & 5,94 \\
\hline CAP & 17,02 & 16,16 & 16,39 & 14,18 & 14,35 & 14,70 \\
\hline
\end{tabular}




\begin{tabular}{lrrrrrr}
\hline $\begin{array}{c}\text { R\$ 128,07 } \\
\text { milhões }\end{array}$ & $\begin{array}{c}\text { Cenário } \\
\mathbf{1 9}\end{array}$ & $\begin{array}{c}\text { Cenário } \\
\mathbf{2 0}\end{array}$ & $\begin{array}{c}\text { Cenário } \\
\mathbf{2 1}\end{array}$ & $\begin{array}{c}\text { Cenário } \\
\mathbf{2 2}\end{array}$ & $\begin{array}{c}\text { Cenário } \\
\mathbf{2 3}\end{array}$ & $\begin{array}{c}\text { Cenário } \\
\mathbf{2 4}\end{array}$ \\
\hline Simulação & AGR & OIND & AGI & MAR & IFIN & OSERV \\
\hline \multicolumn{1}{c}{ AGR } & 0,50 & $-0,10$ & 0,10 & 0,00 & 0,00 & 0,00 \\
OIND & $-0,50$ & $-0,20$ & $-0,30$ & $-0,10$ & $-0,10$ & $-0,20$ \\
AGI & 4,50 & 3,90 & 4,10 & 2,70 & 2,70 & 3,00 \\
MAR & 9,10 & 7,80 & 7,70 & 6,10 & 5,30 & 5,80 \\
IFIN & 0,30 & 0,30 & 0,30 & 0,10 & 1,10 & 0,10 \\
OSERV & $-1,80$ & $-1,60$ & $-1,60$ & $-1,20$ & $-1,20$ & $-1,20$ \\
EX & 336,70 & 286,20 & 283,80 & 192,40 & 198,20 & 216,30 \\
IM & 62,40 & 51,80 & 51,10 & 33,10 & 34,20 & 37,90 \\
W & $-1,80$ & $-1,70$ & $-1,70$ & $-1,30$ & $-1,40$ & $-1,40$ \\
PAGR & 8,70 & 8,10 & 8,20 & 6,50 & 6,60 & 6,90 \\
POIND & 1,50 & 1,40 & 1,40 & 1,10 & 1,20 & 1,20 \\
PAGI & 2,30 & 2,20 & 2,20 & 1,70 & 1,80 & 1,80 \\
PMAR & $-25,80$ & $-24,00$ & $-24,20$ & $-19,10$ & $-19,50$ & $-20,40$ \\
PIFIN & $-23,40$ & $-21,80$ & $-22,00$ & $-17,40$ & $-17,70$ & $-18,50$ \\
POSERV & $-18,00$ & $-16,80$ & $-16,90$ & $-13,40$ & $-13,60$ & $-14,20$ \\
PFX & 0,00 & 0,00 & 0,00 & 0,00 & 0,00 & 0,00 \\
PL & $-75,40$ & $-70,20$ & $-70,70$ & $-55,90$ & $-57,00$ & $-59,40$ \\
PK & 31,00 & 28,90 & 29,10 & 23,00 & 23,50 & 24,50 \\
PW & $-7,30$ & $-6,80$ & $-6,80$ & $-5,40$ & $-5,50$ & $-5,70$ \\
PT & 18,50 & 17,20 & 17,30 & 13,50 & 13,80 & 14,40 \\
FAM & $-20,34$ & $-18,95$ & $-19,10$ & $-15,14$ & $-15,45$ & $-16,09$ \\
GOV & 12,08 & 11,22 & 11,33 & 8,81 & 9,00 & 9,40 \\
CAP & 29,36 & 27,33 & 27,56 & 21,76 & 22,20 & 23,15 \\
\hline
\end{tabular}

Fonte: Dados da pesquisa.

Nota: EX = Exportação; IM = Importação; $\mathrm{W}$ = Índice de bem-estar; PAGR = Preço Agropecuária; POIND = Preço Outras Indústrias; PAGI = Preço Agroindústria; PMAR = Preço Margens; PIFIN = Preço Intermediações Financeiras; POSERV = Preço Outros Serviços; PFX = Taxa de câmbio real; PL = Salário; PK = Renda Capital; PW = Preço bem-estar; PT = Transferência; FAM = Consumidor FAMILIA; GOV = GOVERNO e $\mathrm{CAP}=$ Consumidor CAPITAL.

Para atender a esses percentuais de expansão nas exportações da Agropecuária, ampliaram-se os preços do capital em $11,80 \%$ e $31 \%$, respectivamente. Houve queda nos preços do trabalho da ordem de 43,70\% e $75,40 \%$, respectivamente. Esses resultados apontam para uma situação em que o aumento das exportações exigiu relativamente menos trabalho e, na ausência de inflação (suposição adotada no MAEG), para manter o 
equilíbrio (geral), é necessário queda na remuneração desse fator. A necessidade de investimento requereu um aumento de $17,02 \%$. A renda das famílias decresceu em $-11,83 \%$ e a do governo aumentou em 6,92\%.

Esses resultados são consistentes com os encontrados por Quadros (2004) de queda na renda das famílias brasileiras no período de 1981 a 2002, constatando-se o achatamento da classe média, com respectivo aumento do número de pessoas consideradas em condições miseráveis nesse período pesquisado. De modo semelhante, o IBGE (2005) apresentou dados que indicam queda real da participação da massa salarial brasileira no Produto Interno Bruto (PIB), que se reduziu de 43,5\%, em 1992, para 36,1\%, em 2002.

Nas simulações 3 e 4, o valor total das exportações cresceu numa variação de $127,20 \%$ a $336,70 \%$ e o total das importações variou de $22,10 \%$ a $62,40 \%$, respectivamente. Em termos da balança comercial, estes resultados foram significativos, possibilitando superávit comercial.

Ao analisar cada uma das colunas apresentadas na Tabela 8, observa-se que os setores Agroindústria e Margens apresentaram os maiores aumentos em suas produções, em razão da ampliação nas exportações de seus próprios setores. Dada a grande representatividade do setor Agroindústria para o comércio brasileiro, verifica-se que este apresentou, em termos absolutos, melhor resultado quando comparado ao setor Margens.

Observa-se, também, na Tabela 8, que o setor que exigiu maior aumento no capital $(17,30 \%)$ para atender aos novos níveis de exportações é a Agroindústria. Esse setor necessitou atender imposições e exigências do mercado internacional, haja vista as barreiras comerciais em torno de algumas commodities - caso da carne bovina, suco de laranja, açúcar e complexo soja, principalmente.

Verifica-se que os cenários cujos resultados apresentaram os maiores superávits foram 19, 20 e 21, os quais correspondem aos setores Agropecuário, Outras Indústrias e Agroindústria, respectivamente. Esses resultados podem ser explicados, principalmente, pela conjuntura de preços internacionais favoráveis na qual os itens de maior peso no segmento de produtos primários foram beneficiados. Destacando-se que os produtos do complexo soja foram grandemente favorecidos pela quebra de safra dos Estados Unidos e pelo crescente aumento na demanda de grãos por parte da China, Países Baixos e Polônia. Houve, também, crescimento 
nas exportações de produtos manufaturados, especialmente com relação a suco de laranja, máquinas e equipamentos agrícolas.

\subsection{Comparação dos resultados dos modelos MCS e MAEG}

Fazendo-se uma comparação dos resultados apresentados neste trabalho - simulações 1 e 2 referentes ao modelo da MCS, e simulações 3 e 4 referentes ao modelo aplicado de equilíbrio geral (MAEG) -, observa-se que, para o mesmo percentual de ampliação nas exportações aplicados em ambos os modelos, tem-se que:

a) Com relação à (re)distribuição de renda entre os fatores de produção, ambos os modelos apresentaram as mesmas tendências, ou seja, houve claro benefício ao capital em detrimento do trabalho na maioria dos cenários apresentados.

b) No que se refere à balança comercial, o país foi largamente beneficiado, em qualquer das simulações de expansão nas exportações, obtendo-se superávit em todos os cenários utilizados.

Nas simulações aplicadas no modelo MCS e nas aplicadas no MAEG, os resultados foram bastante semelhantes, o que indica que uma política de expansão das exportações teria forte impacto na balança comercial, possibilitando saldo positivo e ampliação de divisas ao país.

\section{Conclusões}

Este trabalho buscou evidências que pudessem responder a algumas importantes questões que afligem a economia dos países, diante de um comércio externo cada vez mais exigente e competitivo. Desta forma, avaliou-se o desempenho das exportações brasileiras de produtos agropecuários e agroindustriais, numa perspectiva de equilíbrio geral, visando identificar os efeitos da ampliação dessas exportações sobre a balança comercial e sobre a (re)distribuição de renda entre fatores de produção.

Os multiplicadores da MCS apresentaram resultados que indicam que as produções dos setores Outras Indústrias, Outros Serviços e a instituição Família foram as mais impactadas, dadas as expansões nas exportações brasileiras em qualquer dos setores selecionados neste trabalho. Os resultados do MAEG, por sua vez, sugerem que houve favorecimento do 
fator capital em relação ao trabalho com a ampliação das exportações. Ambos os modelos (MCS e MAEG) apresentaram efeitos positivos e significativos na balança comercial brasileira.

Como conclusão final, ressalta-se que os modelos utilizados apontaram uma mesma tendência, o que indica que os choques exógenos (ampliação das exportações) aplicados resultaram em efeitos positivos e significativos na balança comercial brasileira. No entanto, com relação à (re)distribuição de renda, constatou-se que não houve melhoria significativa no padrão distributivo, visto que, na maioria dos cenários, o capital foi o maior beneficiário.

Entre as limitações do trabalho destaca-se que os modelos utilizados (MCS e MAEG) admitem tecnologia com retorno constante à escala e não permite substituição entre fatores na produção, o que restringe seu uso em ambiente dinâmico. Indica-se, também, como uma limitação, a agregação em poucos setores econômicos, o que dificultou sobremaneira uma análise mais específica e detalhada dos resultados das diversas simulações realizadas. Essas limitações podem ser superadas com novas pesquisas que abordem o mesmo tema deste trabalho.

\section{Referências bibliográficas}

BANCO CENTRAL DO BRASIL. Relatório de atividades. 1996. Disponível em: <www.bcb.gov.br/2004 > .

BAUTISTA, R.M.; ROBINSON, S.; TARP, F.; WOBST, P. Policy bias and agricultura: partial and general equilibrium measures. Washington: International Food Policy Research Institute, 1998. 35 p.

BRASIL. Ministério do Desenvolvimento, Indústria e Comércio. Secretaria do Comércio Exterior. Evolução do comércio exterior brasileiro de 1950 a 2003. Disponível em: www.mdic.gov.br. Acesso em: 2004.

BROOKE, A.; KENDRICK, D.; MEERAUS, A. GAMS: a user's guide. Washington: GAMS Development Corporation, 1996. 286.

GINSBURGH, V.; KEYZER, M. The structure of applied general equilibrium models. London: The MIT Press, 1997. 555p.

GÜZEL, H.A., KULSHRESHTHA, S.N. Effects of real exchange rate chan- 
ges on Canadian agriculture: a general equilibrium evaluation. Journal of Policy Modeling, v. 17, n. 6, p. 639-657, 1995.

INSTITUTO BRASILEIRO DE GEOGRAFIA E ESTATÍSTICA - IBGE. Matriz de insumo-produto 1996. Rio de Janeiro: IBGE, 1999.

INSTITUTO BRASILEIRO DE GEOGRAFIA E ESTATÍSTICA - IBGE. Departamento de Contas Nacionais. Sistemas de Contas Nacionais Brasil. Rio de Janeiro, 2005.

QUADROS, W. Brasil: estagnação e crise. São Paulo: GELRE, 2004. 29 p. (Coletânea Gelre - Série Estudos do Trabalho).

RUTHERFORD, T.F. Applied general equilibrium modeling with MPSGE as a GAMS subsystem: an overview of the modeling framework and syntax. Disponível em: < http://www.gams.com/solvers/mpsge/syntax.

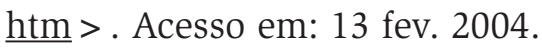

SADOULET, E. ; DE JANVRY, A. Quantitative development policy analysis. Baltimore: The Johns Hopkins University Press, 1995. 397p.

SHOVEN, J. B.; WHALLEY, J. Applying general equilibrium. New York: Cambridge University Press, 1992. 299p.

VIEIRA, W.C. Notas sobre a construção de matrizes de contabilidade social. Economia Rural, Viçosa, ano 9, n. 2, p.30-37, 1998.

Recebido em junho de 2005 e revisto em maio de 2006 